\section{Commentary: Atrioventricular valve insufficiency: Achilles' heel in single-ventricle physiology}

\author{
Osami Honjo, $\mathrm{MD}, \mathrm{PhD}$, and \\ Sachiko Kadowaki, MD, PhD
}

Atrioventricular (AV) valve insufficiency in patients with a functional single ventricle causes significant chronic volume overload to the systemic ventricle, which negatively influences all stages of single-ventricle physiology, resulting in high mortality and failing Fontan circulation. ${ }^{1,2}$ The multicenter study conducted by Arrigoni and colleagues ${ }^{3}$ sheds a light on the long-term influence of AV valve insufficiency on patients with unbalanced AV septal defect (AVSD). Patients with unbalanced AVSD and the common $\mathrm{AV}$ valve are known to have various degrees of $\mathrm{AV}$ valve structural abnormalities, which often hinders successful single-ventricle palliation and maintenance of the Fontan circulation in the long term. ${ }^{2}$ The study provides unique new data on this matter. Firstly, the study includes very long-term follow-up of AV valve function in patients with unbalanced AVSD. Perhaps most important, variability in clinical practice among the participating institutions regarding threshold and timing of surgical intervention to a regurgitant $\mathrm{AV}$ valve gives a unique perspective for patients with significant untreated AV valve insufficiency acting as a control group. The study confirmed what we currently believe when treating patients with singleventricle physiology with a significantly regurgitant $\mathrm{AV}$ valve: concomitant $\mathrm{AV}$ valve repair did not increase mortality nor decrease the rate of Fontan completion, and the patients who had significant $\mathrm{AV}$ valve insufficiency in the follow-up echocardiogram had a significantly lower survival rate. ${ }^{3}$ The findings from this study are consistent

From the Division of Cardiovascular Surgery, Labatt Family Heart Centre, The Hospital for Sick Children, Toronto, Ontario, Canada; and Department of Surgery, University of Toronto, Toronto, Ontario, Canada.

Disclosures: The authors reported no conflicts of interest.

The Journal policy requires editors and reviewers to disclose conflicts of interest and to decline handling or reviewing manuscripts for which they may have a conflict of interest. The editors and reviewers of this article have no conflicts of interest.

Received for publication July 13, 2021; revisions received July 13, 2021; accepted for publication July 13, 2021; available ahead of print July 17, 2021.

Address for reprints: Osami Honjo, MD, PhD, Division of Cardiovascular Surgery, Labatt Family Heart Center, The Hospital for Sick Children, 555 University Ave,

Toronto, Ontario M5G1X8, Canada (E-mail: osami.honjo@sickkids.ca).

J Thorac Cardiovasc Surg 2022;163:1178-9

$0022-5223 / \$ 36.00$

Copyright (c) 2021 by The American Association for Thoracic Surgery

https://doi.org/10.1016/j.jtcvs.2021.07.020

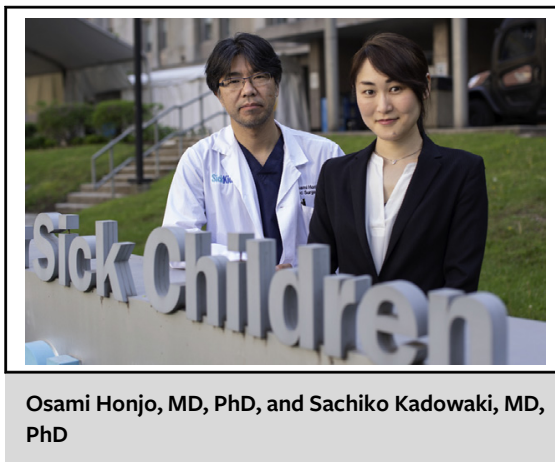

CENTRAL MESSAGE

The BeNe experience confirmed

the importance of maintaining AV

valve competency in patients with

a single-ventricle physiology, and

untreated AV valve insufficiency is

related to lower survival rate.

with another recent, large study conducted by King and colleagues. ${ }^{4}$ The study reported the freedom from Fontan failure in patients with valvular failure at 10 and 20 years after Fontan surgery were $77 \%$ and $54 \%$, respectively, and suggested Fontan circulation was likely to fail in patients with $\mathrm{AV}$ valve failure twice as high as those without $\mathrm{AV}$ valve failure. ${ }^{4}$

One of our studies, which investigated the mechanism of AV valve insufficiency in patients with single-ventricle physiology, demonstrated that approximately $85 \%$ of the AV valve with significant insufficiency had structural abnormalities such as leaflet dysplasia, prolapse, cleft, or double orifice. ${ }^{1}$ Moreover, our follow-up study showed that leaflet dysplasia and residual AV valve insufficiency are identified as predictors for AV valve re-repair or replacement. ${ }^{5}$ There was a notion in the past that the volume unloading operation, such as bidirectional cavopulmonary shunt, might improve the degree of AV valve insufficiency. Although we sometimes see this phenomenon in patients with minor $A V$ valve insufficiency without major $A V$ valve structural abnormalities, the majority of the cases with significant $A V$ valve insufficiency will not be improved only by the volume-unloading surgery. Lastly, the systemic single ventricle that is exposed to chronic volume overload caused by $\mathrm{AV}$ valve insufficiency may have significant myocardial dysfunction following successful AV valve repair, which adversely influences single-ventricle physiology. ${ }^{1}$ This is additional rationale to intervene in significant $\mathrm{AV}$ valve 
insufficiency earlier than later before irreversible myocardial damage occurs. The investigators from the BeNe experience-the scientific cooperation of Belgium and Netherlands-should be congratulated on the wellconducted cohort study, which adds new knowledge in the management of patients with single-ventricle physiology.

\section{References}

1. Honjo O, Atlin CR, Mertens L, Al-Radi OO, Redington AN, Caldarone CA, et al. Atrioventricular valve repair in patients with functional single-ventricle physi- ology: impact of ventricular and valve function and morphology on survival and reintervention. J Thorac Cardiovasc Surg. 2011;142:326-35.

2. Ono M, Burri M, Mayr B, Anderl L, Strbad M, Cleuziou J, et al. Risk factors for failed Fontan procedure after stage 2 palliation. Ann Thorac Surg. 2021;112: $610-8$

3. Arrigoni SC, Jsselhof RI, Postmus D, Vonk JM, François K, Bové T, et al. Longterm outcome of atrioventricular septal defect and single ventricle: a multicenter study. J Thorac Cardiovasc Surg. 2022;163:1166-75.

4. King G, Ayer J, Celermajer D, Zentner D, Justo R, Disney P, et al. Atrioventricular valve failure in Fontan palliation. J Am Coll Cardiol. 2019;73:810-22.

5. Kotani Y, Chetan D, Atlin CR, Mertens LL, Jegatheeswaran A, Caldarone CA et al. Longevity and durability of atrioventricular valve repair in single-ventricle patients. Ann Thorac Surg. 2012;94:2061-9. 